\title{
Healthcare disparities among orthopedic trauma patients in the USA: socio- demographic factors influence the management of calcaneus fractures
}

\author{
Boris A. Zelle ${ }^{1 *}$, Nicolas A. Morton-Gonzaba ${ }^{1}$, Christopher F. Adcock ${ }^{1}$, John V. Lacci ${ }^{1}$, Khang H. Dang ${ }^{1}$ and Ali Seifi ${ }^{2}$
}

\begin{abstract}
Background: Socio-demographic factors have been suggested to contribute to differences in healthcare utilization for several elective orthopedic procedures. Reports on disparities in utilization of orthopedic trauma procedures remain limited. The purpose of our study is to assess the roles of clinical and socio-demographic variables in utilization of operative fixation of calcaneus fractures in the USA.

Methods: The National Inpatient Sample (NIS) dataset was used to analyze all patients from 2005 to 2014 with closed calcaneal fractures. Multivariate logistic regression analyses were performed to evaluate the impact of clinical and socio-demographic variables on the utilization of surgical versus non-surgical treatment.

Results: A total of 17,156 patients with closed calcaneus fractures were identified. Operative treatment was rendered in 7039 patients (41.03\%). A multivariate logistic regression demonstrated multiple clinical and sociodemographic factors to significantly influence the utilization of surgical treatment including age, gender, insurance status, race/ethnicity, income, diabetes, peripheral vascular disease, psychosis, drug abuse, and alcohol abuse $(p<0.05)$. In addition, hospital size and hospital type (teaching versus non-teaching) showed a statistically significant difference $(p<0.05)$.

Conclusions: Besides different clinical variables, we identified several socio-demographic factors influencing the utilization of surgical treatment of calcaneus fractures in the US patient population. Further studies need to identify the specific patient-related, provider-related, and system-related factors leading to these disparities.
\end{abstract}

Keywords: Calcaneus, Fracture, Open reduction internal fixation, Trends, Socioeconomic

\section{Background}

The treatment of calcaneus fractures remains challenging and controversial. Historically, these injuries were managed non-operatively given the high concern for postoperative morbidity [1]. Over the past decades, improvements in diagnostic imaging, surgical techniques, understanding of the soft tissue injury, and advances in surgical implants have improved clinical outcomes [2-4]. Open reduction and internal fixation remains a standard treatment option for displaced intraarticular calcaneus fractures [3, 4].

\footnotetext{
* Correspondence: boris.zelle@gmail.com; zelle@uthscsa.edu

${ }^{1}$ Department of Orthopaedic Surgery, UT Health San Antonio, 7703 Floyd

Curl Dr, MC-7774, San Antonio, TX 78229, USA

Full list of author information is available at the end of the article
}

Despite these improvements, the risk of soft tissue complications remains relatively high and patients with certain risk factors, such as smoking and diabetes, have been suggested to be unfavorable candidates for this procedure [5]. In addition, the question remains to what extent different socio-demographic factors, such as race, insurance status, and income, may potentially contribute to differences in healthcare utilization of surgical fixation of calcaneus fractures.

Recent reports have emphasized significant ethnic and racial disparities in utilization of elective orthopedic procedures, such as arthroplasty, carpal tunnel release, and lumbar spinal fusions [6-9]. In particular, ethnic and racial minorities seem to be less likely to utilize elective

(c) The Author(s). 2019 Open Access This article is distributed under the terms of the Creative Commons Attribution 4.0 International License (http://creativecommons.org/licenses/by/4.0/), which permits unrestricted use, distribution, and reproduction in any medium, provided you give appropriate credit to the original author(s) and the source, provide a link to the Creative Commons license, and indicate if changes were made. The Creative Commons Public Domain Dedication waiver (http://creativecommons.org/publicdomain/zero/1.0/) applies to the data made available in this article, unless otherwise stated. 
orthopedic procedures. The exact etiology for these healthcare disparities is not fully known. Most likely, the underlying reasons for these findings are multifactorial and may include patient-related factors as well as provider-related factors. In addition, system-related factors, such as access to healthcare, may further contribute to this phenomenon [7,10-13]. Most of the data on ethnic and racial disparities regarding utilization of orthopedic procedures refers to elective orthopedic procedures. Regarding orthopedic trauma procedures, a recent report suggested increased rates of fixation of clavicle fractures in Caucasians and patients of higher socioeconomic status [14]. However, studies from the orthopedic trauma literature depicting healthcare utilization disparities remain limited.

The goal of our study is to further assess the roles of socio-demographic, specifically race, and other clinical variables in operative fixation of calcaneus fractures in the USA. We hypothesize that several socio-demographic variables are associated with decreased rates of fixation of these fractures.

\section{Methods}

\section{Database}

The Agency for Healthcare Research and Quality developed the National Inpatient Sample (NIS), which is a part of the Healthcare Cost and Utilization Project (HCUP). The NIS database is publicly available and is comprised of an approximately $20 \%$ stratified sample of all discharges at US hospitals, excluding rehabilitation and long-term acute care facilities. Information includes diagnosis/procedure codes (International Classification of Disease version 9 Clinical Modification, ICD-9 CM; Current Procedure Terminology, CPT), demographic data, and insurance. This database was chosen because it allowed regression analyses of treatment trends and demographic data. The entry input of patient's comorbidities has shown to be accurate through previous studies and has been tested through the Elixhauser Comorbidity Software [15]. The study was determined to be non-regulated research and did not qualify for review by the Institutional Review Board (IRB) of our institution.

\section{Patients}

From the 2005-2014 NIS database sets, all discharges with a closed calcaneus fracture (code 825.0) were included in this study. Observations with the ICD-9 CM codes 825.1; 825.20-825.29; 825.30-825.39 were excluded from this study as they code for other foot fractures. Since other foot fractures were excluded, surgical fixation of calcaneus fracture was identified through the ICD-9 CM code 79.37. Patients with missing data were excluded. Several potentially confounding clinical and socio-demographic variables were obtained from the database and tested for any differences between the operative and non-operative group. The socio-demographic variables included age, sex, race/ethnicity, estimated median household income quartile based on zip code, and insurance status. Potentially confounding comorbidities included diabetes mellitus, acquired immune deficiency syndrome (AIDS), illicit drug abuse, peripheral vascular diseases, smoking status, alcohol abuse, obesity, psychosis, and depression. Additional potentially confounding variables included hospital type (teaching versus non-teaching) and hospital size, as divided by number of beds into small, medium, and large.

\section{Statistical analysis}

The statistical analyses were performed on a total of 17 , 156 discharged patients who were identified by the inclusion and exclusion criteria as above. All statistical analyses were performed using Stata 15.1 (StataCorp, College Station, TX, USA). All continuous variables were tested for normal distribution. Normally distributed data was reported as means with standard deviation (SD). Not normally distributed data was reported as median with range. The univariate analysis used $T$ tests for continuous variables and chi-square testing for noncontinuous variables. All clinical and socio-demographic variables were tested for statistical significance in a univariate analysis. All clinical and socio-demographic variables that demonstrated statistical significance at the level of $p<0.05$ in the univariate analysis were enrolled into the multivariate regression analysis. A multivariate regression model was created by including all statistically significant clinical and socio-demographic variables found in the univariate analysis. The independent variables included in the multivariate regression analysis were age, sex, race/ethnicity, estimated median household income, insurance status, diabetes mellitus (complicated and uncomplicated), AIDS, illicit drug abuse, peripheral vascular diseases, alcohol abuse, obesity, psychosis, and depression. In addition, hospital size (by number of beds) and type of hospital (teaching versus non-teaching) were included in the multivariate regression. Utilization of open reduction and internal fixation of calcaneus fracture was the dependent variable.

\section{Results}

Between 2005 and 2014, a total of 17,156 patients were included for participation in this study. The sociodemographic data of our patient sample is shown in Table 1. 10,117 patients underwent non-operative management of their calcaneus fracture while 7039 patients underwent open reduction and internal fixation. The univariate analysis suggested that as compared to the operative group, patients who were treated non-operatively were more likely to be older and female $(p<0.001)$. 
Table 1 Socio-demographic variables in patients with calcaneus fractures, univariate comparison between non-operative and operative treatment

\begin{tabular}{|c|c|c|c|c|}
\hline & Total & Non-operative & Operative & $p$ \\
\hline Sample size & 17,156 & $10,117(58.97 \%)$ & $7039(41.03 \%)$ & \\
\hline Age (mean $\pm S D$ ), years & $47.79 \pm 17.13$ & $49.20 \pm 18.48$ & $45.78 \pm 14.75$ & $<0.001$ \\
\hline Female, $n(\%)$ & 5649 & 3756 (37.13\%) & 1893 (26.89\%) & $<0.001$ \\
\hline Payer, $n$ (\%) & & & & $<0.001$ \\
\hline Medicare & 3043 & $2230(73.28 \%)$ & $813(26.72 \%)$ & \\
\hline Medicaid & 2027 & $1284(63.34 \%)$ & $743(36.66 \%)$ & \\
\hline Private payer & 6860 & 3656 (53.29\%) & 3204 (46.71\%) & \\
\hline Self-payer & 2225 & 1391 (62.51\%) & $834(37.49 \%)$ & \\
\hline No charge & 288 & $158(54.86 \%)$ & $130(45.14 \%)$ & \\
\hline Other & 2713 & $1398(51.52 \%)$ & $1315(48.48 \%)$ & \\
\hline Race/ethnicity, n (\%) & & & & $<0.001$ \\
\hline White & 12,693 & 7419 (58.44\%) & $5274(41.46 \%)$ & \\
\hline African-American & 1465 & $971(66.27 \%)$ & $494(33.73 \%)$ & \\
\hline Hispanic & 1927 & 1152 (59.78\%) & 775 (40.22\%) & \\
\hline Asian & 360 & $186(51.66 \%)$ & $174(48.34 \%)$ & \\
\hline Native American & 112 & $73(65.17 \%)$ & $39(34.83 \%)$ & \\
\hline Other & 599 & 316 (52.75\%) & $283(47.25 \%)$ & \\
\hline Income ${ }^{*}, n(\%)$ & & & & $<0.001$ \\
\hline 0-24th percentile & 4889 & 3099 (63.38\%) & 1790 (36.62\%) & \\
\hline 25-49th percentile & 4363 & $2578(59.08 \%)$ & 1785 (40.92\%) & \\
\hline 50-74th percentile & 4221 & $2418(57.28 \%)$ & 1803 (42.72\%) & \\
\hline 75-100th percentile & 3683 & $2022(54.90 \%)$ & $1661(45.10 \%)$ & \\
\hline Teaching hospital/location, n (\%) & & & & $<0.001$ \\
\hline Rural & 1241 & $850(68.49 \%)$ & 391 (31.51\%) & \\
\hline Urban non-teaching & 5430 & 3149 (57.99\%) & $2281(42.01 \%)$ & \\
\hline Urban teaching & 10,299 & 6007 (58.32\%) & $4292(41.68 \%)$ & \\
\hline Hospital size (number of beds) & & & & 0.036 \\
\hline Small & 1833 & $1046(57.06 \%)$ & 787 (42.93\%) & \\
\hline Medium & 4065 & $2457(60.44 \%)$ & $1608(39.56 \%)$ & \\
\hline Large & 11,072 & $6503(58.73 \%)$ & 4569 (41.27\%) & \\
\hline
\end{tabular}

Race and ethnicity were significantly different between the non-operative and the operative group $(p<0.001)$, whereby the rates of surgical fixation were lower among African-American and Hispanic patients. In addition, the insurance status, estimated median household income based on zip code, hospital type (teaching versus non-teaching), and hospital size showed statistically significant differences in the univariate analysis $(p<0.001)$. Moreover, we identified several clinical variables that were associated with a significantly lower rate of surgical fixation as per the univariate analysis (Table 2). These clinical variables included diabetes mellitus (complicated and uncomplicated), AIDS, illicit drug abuse, peripheral vascular diseases, alcohol abuse, psychosis, depression, and obesity $(p<0.05)$.
The multivariate logistic regression demonstrated that several clinical and socio-demographic variables significantly influenced the type of treatment (Table 3). The socio-demographic variables associated with a significantly lower utilization of open reduction and internal fixation included older age, female gender, Medicare, minority status (African Americans and Hispanics), and lower estimated income by zip code $(p<0.05)$. Clinical comorbidities associated with a significantly lower utilization of surgical treatment included diabetes mellitus (complicated and uncomplicated), illicit drug abuse, peripheral vascular diseases, alcohol abuse, and psychosis $(p<0.05)$. In addition, it was recorded that the rates of surgical fixation were lower at rural hospitals as well as hospitals with a smaller number of beds $(p<0.05)$. 
Table 2 Clinical variables in patients with calcaneus fractures, univariate comparison between non-operative and operative treatment

\begin{tabular}{|c|c|c|c|c|}
\hline & Total & Non-operative & Operative & $p$ \\
\hline Sample size & 17,156 & $10,117(58.97 \%)$ & $7039(41.03 \%)$ & \\
\hline Diabetes, uncomplicated & 1386 & $936(67.53 \%)$ & $450(32.47 \%)$ & $<0.001$ \\
\hline Diabetes, with chronic complications & 495 & $392(79.19 \%)$ & $103(20.81 \%)$ & $<0.001$ \\
\hline AIDS & 32 & $25(78.13 \%)$ & $7(21.88 \%)$ & 0.026 \\
\hline Drug abuse & 1076 & $798(74.16 \%)$ & $278(25.83 \%)$ & $<0.001$ \\
\hline Peripheral vascular disorders & 656 & $483(73.63 \%)$ & $173(26.37 \%)$ & $<0.001$ \\
\hline Alcohol abuse & 1333 & $1024(76.82 \%)$ & $309(23.18 \%)$ & $<0.001$ \\
\hline Psychosis & 151 & $114(75.50 \%)$ & $37(24.50 \%)$ & $<0.001$ \\
\hline Depression & 1271 & $824(64.83 \%)$ & $447(35.17 \%)$ & $<0.001$ \\
\hline Obesity & 789 & $514(65.15 \%)$ & $275(34.85 \%)$ & $<0.001$ \\
\hline Smoking & 4213 & 2490 (59.10\%) & $1723(40.90 \%)$ & 0.85 \\
\hline
\end{tabular}

\section{Discussion}

While healthcare utilization disparities have been shown in several areas of orthopedics, such as arthroplasty, upper extremity, and spinal surgeries, the literature has been limited within the field of orthopedic trauma $[6,8,16]$. Our study showed that several factors influence the treatment of closed calcaneus fractures in the US patient population. Expectedly, utilization of open reduction and internal fixation was influenced by medical comorbidities including diabetes, peripheral vascular disease, history of alcohol abuse, history of drug abuse, and psychoses. In addition, it is an expected finding that the rates of surgical treatment were lower at small hospitals and non-teaching facilities. Interestingly, we were able to identify specific socio-demographic factors with a significant influence on utilization of open reduction and internal fixation of calcaneus fractures. Thus, AfricanAmerican patients and Hispanic patients with calcaneus fractures were less likely to undergo open reduction and internal fixation as compared to Caucasian patients, whereas Asian patients with calcaneus fractures seemed more likely to undergo surgery. In addition, insurance status and median zip code income showed a significant influence on the type of treatment.

Our study has both strengths and limitations. The data presented in this study demonstrates socio-demographic disparities regarding utilization of surgical fixation of calcaneus fractures. However, we do not have any research data to explain the exact reasons for these findings. Thus, future investigations may address specific patient-related, provider-related, and system-related factors contributing to this phenomenon. In addition, our data was retrieved from a multicenter database. This is inherently associated with certain limitations, such as variable data entry. In addition, the database used in this study is limited to inpatient admissions and does not account for those patients with calcaneus fractures treated on an outpatient basis. This certainly introduces a potential selection bias due to an over-representation of patients with potentially more comorbidities and social issues. Moreover, we were unable to collect fracturespecific information, such as fracture classification and the associated soft tissue injury. We identified patients with the diagnosis of a closed calcaneus fracture as per ICD-9 code, and we do not have any radiographic data to record fracture displacement, comminution, or intraarticular involvement. However, with regard to our main study question of racial and social disparities, we assume that the severity of fractures was equally distributed among patients of different race and socioeconomic status. We, therefore, feel that the lack of radiologic data did not introduce any significant bias into the study with regard to our main results.

Racial and social healthcare disparities have been identified within different elective areas of orthopedic surgery, such as hip and knee arthroplasty, shoulder arthroplasty, ankle arthroplasty, spinal fusion, cubital and carpal tunnel surgery, elective hardware removal following pediatric femoral shaft fractures, and treatment of meniscal tears $[6-9,13,16-22]$. In particular, minorities were significantly less likely to undergo these elective orthopedic procedures. Regarding healthcare disparities in orthopedic trauma patients, a recent report by Schairer et al. [14] suggested increased rates of fixation of clavicle fractures in Caucasians and patients of higher socioeconomic status. However, to our best knowledge, reports on racial and social disparities regarding utilization of orthopedic trauma procedures remain limited. We can only speculate on why these healthcare disparities have gained little attention in the orthopedic trauma literature. As a possible explanation, we suggest that there may be the common misconception that in orthopedic trauma, the decision of operative versus non-operative treatment may be solely based on the injury pattern and the actual fracture pathology. 
Table 3 Multivariate logistic regression

\begin{tabular}{|c|c|c|c|c|}
\hline \multirow{2}{*}{$\overline{\text { Age }}$} & \multirow{2}{*}{$\begin{array}{l}\text { Odds ratio } \\
0.994\end{array}$} & \multicolumn{2}{|c|}{ 95\% confidence interval } & \multirow{2}{*}{$\frac{p}{<0.001}$} \\
\hline & & 0.992 & 0.997 & \\
\hline Female & 0.692 & 0.643 & 0.745 & $<0.001$ \\
\hline \multicolumn{5}{|l|}{ Payer, (base-Medicare) } \\
\hline Medicaid & 1.352 & 1.172 & 1.559 & $<0.001$ \\
\hline Private payer & 1.746 & 1.565 & 1.949 & $<0.001$ \\
\hline Self-payer & 1.224 & 1.064 & 1.409 & 0.005 \\
\hline No charge & 1.688 & 1.296 & 2.199 & $<0.001$ \\
\hline Other & 1.717 & 1.509 & 1.955 & $<0.001$ \\
\hline \multicolumn{5}{|l|}{ Race, (base-White) } \\
\hline African-American & 0.807 & 0.714 & 0.911 & 0.001 \\
\hline Hispanic & 0.895 & 0.806 & 0.993 & 0.038 \\
\hline Asian & 1.296 & 1.043 & 1.611 & 0.019 \\
\hline Native American & 0.867 & 0.566 & 1.329 & 0.514 \\
\hline Other & 1.160 & 0.977 & 1.376 & 0.089 \\
\hline \multicolumn{5}{|l|}{$\begin{array}{l}\text { Income (base-0-24th } \\
\text { percentile) }\end{array}$} \\
\hline 25-49th percentile & 1.106 & 1.013 & 1.208 & 0.025 \\
\hline 50-74th percentile & 1.137 & 1.039 & 1.245 & 0.005 \\
\hline 75-100th percentile & 1.233 & 1.121 & 1.356 & $<0.001$ \\
\hline \multicolumn{5}{|l|}{$\begin{array}{l}\text { Teaching hospital/location } \\
\text { (base-urban non-teaching) }\end{array}$} \\
\hline Rural & 0.657 & 0.572 & 0.754 & $<0.001$ \\
\hline Urban teaching & 0.979 & 0.913 & 1.050 & 0.565 \\
\hline \multicolumn{5}{|l|}{ Hospital size (base—small) } \\
\hline Medium & 0.874 & 0.778 & 0.982 & 0.024 \\
\hline Large & 0.919 & 0.828 & 1.020 & 0.114 \\
\hline \multicolumn{5}{|l|}{ Comorbidities } \\
\hline Diabetes, uncomplicated & 0.802 & 0.708 & 0.909 & 0.001 \\
\hline $\begin{array}{l}\text { Diabetes, with chronic } \\
\text { complications }\end{array}$ & 0.536 & 0.426 & 0.676 & $<0.001$ \\
\hline AIDS & 0.585 & 0.243 & 1.408 & 0.232 \\
\hline Drug abuse & 0.567 & 0.488 & 0.660 & $<0.001$ \\
\hline Peripheral vascular & 0.401 & 0.297 & 0.540 & $<0.001$ \\
\hline Alcohol abuse & 0.414 & 0.361 & 0.476 & $<0.001$ \\
\hline Psychosis & 0.728 & 0.612 & 0.866 & $<0.001$ \\
\hline Depression & 0.961 & 0.847 & 1.091 & 0.547 \\
\hline Obesity & 0.976 & 0.832 & 1.146 & 0.775 \\
\hline
\end{tabular}

However, the role of open reduction and internal fixation in the treatment of calcaneus fractures is not yet fully defined, and non-operative treatment frequently remains a feasible treatment option [2]. Thus, the indication for open reduction and internal fixation in calcaneus fractures depends on various factors. Besides the fracture pattern, the patient's surgical risk factors, such as smoking and diabetes, play a significant role in the decision making [5]. Given the relatively high risk of soft tissue complications associated with this surgical procedure, careful risk/benefit discussions frequently play a predominant role in the shared decision-making process. This complex decision-making process is certainly influenced by patients' preferences as well as surgeons' preferences, which potentially may be associated with the risk of introducing bias based on the patient's sociodemographics. 
While our study demonstrated socio-demographic disparities regarding utilization of open reduction and internal fixation of calcaneus fractures, the exact reasons for these disparities remain unclear. Examining the exact causation for these findings observed in our study is beyond the scope of the current analysis. Data from elective orthopedic specialties has suggested various patient-related, providerrelated, and system-related factors which may play a role for racial and social disparities regarding utilization of orthopedic procedures. With regard to patient-related factors, different studies have shown that African-American patients are less willing to consider surgical treatment options for their hip and knee osteoarthritis [11, 23-25]. In addition, provider-related factors have been suggested to contribute to racial and social disparities in orthopedic surgery. Thus, it has been reported that orthopedic providers have less relationship building communications with African-American patients as compared to white patients [26]. Moreover, system-related factors, such as access to healthcare, may contribute to these disparities. Jancuska et al. [8] reported that Medicaid patients and minorities were less likely to undergo spinal fusion at high-volume centers suggesting access issues for these vulnerable populations. Also, Bach et al. [27] reported significant difficulty for providers to access resources for African Americans, including subspecialty referrals, diagnostic imaging, hospital admission, and high-quality ancillary services. Although this data from elective orthopedic procedures cannot be extrapolated to orthopedic trauma patients, we suggest that the racial and social disparities observed in our study are multifactorial and may include various patient-related, providerrelated, and system-related factors.

\section{Conclusions}

In conclusion, our study demonstrated the significant influence of clinical and socio-demographic variables on utilization of open reduction and internal fixation of calcaneus fractures in the US patient population. Besides the influence of several clinical comorbidities, our study showed decreased utilization for minorities, patients from lower income zip codes, and patients without private insurance. Future studies may investigate the specific patient-related, provider-related, and system-related factors that are contributing to healthcare disparities within orthopedic trauma surgery.

\footnotetext{
Abbreviations

AIDS: Acquired immune deficiency syndrome; CPT: Current Procedure Terminology; HCUP: Healthcare Cost and Utilization Project; ICD9: International Classification of Disease version 9; IRB: Institutional Review Board; NIS: National Inpatient Sample; SD: Standard deviation
}

\section{Authors' contributions}

BAZ made substantial contributions to the conception and design, interpretation of data, manuscript preparation, and revisions. NAM-G and CFA made substantial contributions to the conception and design, interpretation of data, and preparation of the manuscript. JVL made substantial contributions to the conception and design, data acquisition and analysis, and manuscript review. KHD made substantial contributions to data analysis and manuscript writing. AS made substantial contributions to conception and design, acquisition of data, and manuscript review. All authors read and approved the final manuscript.

\section{Funding}

No external funding was obtained for purposes of this study.

Availability of data and materials

The datasets generated and/or analyzed during the current study are publicly available.

Ethics approval and consent to participate

This study was approved by the Institutional Review Board of University of Texas Health at San Antonio.

\section{Consent for publication}

There is no information with individual personal data, so no consent for publication was needed.

\section{Competing interests}

$\mathrm{BAZ}$ has received consultant fees from $\mathrm{KCl}$; speaker fees from $\mathrm{AO}$ North America; research grants from DepuySynthes, $\mathrm{KCl}$, and the Orthopedic Trauma Association; and educational grant support from Smith and Nephew Inc. He serves on the editorial board of International Orthopedics, Journal of Orthopedic Trauma, and Patients Safety in Surgery. None of these activities are related to the content of this article. The remaining authors declare that they have no competing interests.

\section{Author details}

${ }^{1}$ Department of Orthopaedic Surgery, UT Health San Antonio, 7703 Floyd Curl Dr, MC-7774, San Antonio, TX 78229, USA. ${ }^{2}$ Department of

Neurosurgery-Neuro Critical Care, UT Health San Antonio, San Antonio, TX, USA.

Received: 1 August 2019 Accepted: 4 October 2019

Published online: 12 November 2019

\section{References}

1. Lindsay WR, Dewar FP. Fractures of the os calcis. Am J Surg. 1958;95:555-76.

2. Buckley R, Tough S, McCormack R, et al. Operative compared with nonoperative treatment of displaced intra-articular calcaneal fractures: a prospective, randomized, controlled multicenter trial. J Bone Joint Surg Am. 2002;84-A:1733-44.

3. Sanders R, Fortin P, DiPasquale T, Walling A. Operative treatment in 120 displaced intraarticular calcaneal fractures: results using a prognostic computed tomography scan classification. Clin Orthop. 1993;290:87-95.

4. Sanders R, Vaupel ZM, Erdogan M, Downes K. Operative treatment of displaced intraarticular calcaneal fractures: long-term (10-20 years) results in 108 fractures using a prognostic CT classification. J Orthop Trauma. 2014;28: 551-63.

5. Folk JW, Starr AJ, Early JS. Early wound complications of operative treatment of calcaneus fractures: analysis of 190 fractures. J Orthop Trauma. 1999:13: 369-72.

6. Day CS, Makhni EC, Mejia E, Lage DE, Rozental TD. Carpal and cubital tunnel syndrome: who gets surgery? Clin Orthop. 2010;468:1796-803.

7. Dodwell E, Wright J, Widmann R, Edobor-Osula F, Pan T-J, Lyman S. Socioeconomic factors are associated with trends in treatment of pediatric femoral shaft fractures, and subsequent implant removal in New York state. J Pediatr Orthop. 2016;36:459-64.

8. Jancuska JM, Hutzler L, Protopsaltis TS, Bendo JA, Bosco J. Utilization of lumbar spinal fusion in New York state: trends and disparities. Spine. 2016; 41:1508-14

9. Singh JA, Lu X, Rosenthal GE, Ibrahim S, Cram P. Racial disparities in knee and hip total joint arthroplasty: an 18-year analysis of national Medicare data. Ann Rheum Dis. 2014;73:2107-15.

10. Dykes DC, White AA. Getting to equal: strategies to understand and eliminate general and orthopaedic healthcare disparities. Clin Orthop. 2009; 467:2598-605. 
11. Hausmann LRM, Mor M, Hanusa BH, et al. The effect of patient race on total joint replacement recommendations and utilization in the orthopedic setting. J Gen Intern Med. 2010;25:982-8.

12. Hausmann LRM, Hanusa BH, Kresevic DM, et al. Orthopedic communication about osteoarthritis treatment: does patient race matter? Arthritis Care Res. 2011;63:635-42.

13. Sood A, Gonzalez-Lomas G, Gehrmann R. Influence of health insurance status on the timing of surgery and treatment of bucket-handle meniscus tears. Orthop J Sports Med. 2015;3:2325967115584883.

14. Schairer WW, Nwachukwu BU, Warren RF, Dines DM, Gulotta LV. Operative fixation for clavicle fractures-socioeconomic differences persist despite overall population increases in utilization. J Orthop Trauma. 2017;31:e167-72.

15. Fortin Y, Crispo JA, Cohen D, McNair DS, Mattison DR, Krewski D. External validation and comparison of two variants of the Elixhauser comorbidity measures for all-cause mortality. PLoS One. 2017:12(3):e0174379.

16. Singh JA, Ramachandran R. Persisting racial disparities in total shoulder arthroplasty utilization and outcomes. J Racial Ethn Health Disparities. 2016; 3:259-66.

17. Kopec JA, Sayre EC, Schwartz TA, et al. Occurrence of radiographic osteoarthritis of the knee and hip among African Americans and whites: a population-based prospective cohort study. Arthritis Care Res. 2013;65:928-35.

18. Jordan JM, Helmick CG, Renner JB, et al. Prevalence of knee symptoms and radiographic and symptomatic knee osteoarthritis in African Americans and Caucasians: the Johnston County osteoarthritis project. J Rheumatol. 2007;34:172-80.

19. Lurie N. Health disparities--less talk, more action. N Engl J Med. 2005;353: 727-9.

20. Martsolf GR, Barrett ML, Weiss AJ, et al. Impact of race/ethnicity and socioeconomic status on risk-adjusted hospital readmission rates following hip and knee arthroplasty. J Bone Joint Surg Am. 2016;98:1385-91.

21. Singh JA, Ramachandran R. Racial disparities in total ankle arthroplasty utilization and outcomes. Arthritis Res Ther. 2015;17.

22. Yu S, Mahure SA, Branch N, Mollon B, Zuckerman JD. Impact of race and gender on utilization rate of total shoulder arthroplasty. Orthopedics. 2016; 39:e538-44.

23. Ibrahim SA, Siminoff $L A$, Burant $C J$, Kwoh CK. Differences in expectations of outcome mediate African American/white patient differences in "willingness" to consider joint replacement. Arthritis Rheum. 2002;46:2429-35.

24. Kwoh CK, Vina ER, Cloonan YK, Hannon MJ, Boudreau RM, Ibrahim SA. Determinants of patient preferences for total knee replacement: AfricanAmericans and whites. Arthritis Res Ther. 2015;17:348.

25. Suarez-Almazor ME, Souchek J, Kelly PA, et al. Ethnic variation in knee replacement: patient preferences or uninformed disparity? Arch Intern Med. 2005:165:1117-24

26. Levinson W, Hudak PL, Feldman JJ, et al. "It's not what you say ...": racial disparities in communication between orthopedic surgeons and patients. Med Care. 2008;46:410-6.

27. Bach PB, Pham HH, Schrag D, Tate RC, Hargraves JL. Primary care physicians who treat blacks and whites. N Engl J Med. 2004;351:575-84.

\section{Publisher's Note}

Springer Nature remains neutral with regard to jurisdictional claims in published maps and institutional affiliations.

Ready to submit your research? Choose BMC and benefit from:

- fast, convenient online submission

- thorough peer review by experienced researchers in your field

- rapid publication on acceptance

- support for research data, including large and complex data types

- gold Open Access which fosters wider collaboration and increased citations

- maximum visibility for your research: over $100 \mathrm{M}$ website views per year

At $\mathrm{BMC}$, research is always in progress.

Learn more biomedcentral.com/submissions 